\title{
Production of Immunoassay Detection Reagent
}

National Cancer Institute

\section{Source}

National Cancer Institute. Production of Immunoassay Detection Reagent. NCI

Thesaurus. Code C113048.

The production of antigen and antibody detection components. 